\title{
The Demands of a Professional Ballet Schedule: A Five-Season Analysis
}

\author{
Joseph W. Shaw * 1,2, Adam M. Mattiussi ${ }^{1,2}$, Derrick D. Brown ${ }^{3}$, Sean Williams ${ }^{4}$, \\ Matthew Springham ${ }^{1,2}$, Charles R. Pedlar ${ }^{1,5}$, and Jamie Tallent ${ }^{1,6}$ \\ ${ }^{1}$ Faculty of Sport, Allied Health and Performance Science, St Mary's University, Twickenham, United Kingdom \\ ${ }^{2}$ Ballet Healthcare, The Royal Ballet, Royal Opera House, London, United Kingdom \\ ${ }^{3}$ Institute of Sport Science, Dance Science, University of Bern, Bern, Switzerland \\ ${ }^{4}$ Department for Health, University of Bath, Bath, United Kingdom \\ ${ }^{5}$ Institute of Sport, Exercise, and Health, Division of Surgery and Interventional Science, University College London, \\ London, United Kingdom \\ ${ }^{6}$ Department of Sport, Exercise and Rehabilitation Sciences, University of Essex, Essex, UK
}

August 9, 2021

\begin{abstract}
Periodizing rehearsal and performance schedules in professional ballet is difficult given a lack of published longitudinal data. We aimed to describe the structure of a professional ballet season, and identify factors associated with inter-dancer and inter-production variation in dance hours. Scheduling data were collected from 123 dancers over five seasons at The Royal Ballet. Linear mixed effects models were used to evaluate differences in weekly dance hours and performance counts across sexes, company ranks, and months. Random forest regressions were used to investigate factors associated with the variation in rehearsal hours across different productions. Performance congestion was observed in December, whereas total dance hours peaked between January and April. Differences in weekly dance hours were observed between company ranks $(p$ $<.001$, range in means: $\left.19.1-27.5 \mathrm{~h} \cdot \mathrm{week}^{-1}\right)$. Seasonal performance counts varied across company ranks $(p<.001)$, ranging from $28,95 \%$ CI $[22,35]$ in principals, to $113,95 \%$ CI $[108,118]$ in artists. Rehearsal durations were greatest in preparation for newly choreographed and longer ballets. Dancers creating roles in new ballets completed considerably more rehearsal hours than for existing ballet. These results provide a basis for the implementation of rehearsal and repertoire periodization in professional ballet.
\end{abstract}

*Corresponding Author: Joseph W. Shaw (joseph.shaw@stmarys.ac.uk) All authors have read and approved this version of the manuscript for pre-print. Authors JS@JosephShaw_,AM @AdamMattiussi,DB@DDBrown_, SW @statman_sean, MS @MattSpringham, $\mathrm{CP} @$ PedlarCR and JT @JamieTallent can be reached on Twitter.

Please cite as: Shaw, J.W., Mattiussi, A.M., Brown, D.D., Williams, S., Springham, M., Pedlar, C., \& Tallent, J. (2021). The Demands of a Professional Ballet Schedule: A Five-Season Analysis. SportR $\chi i v$. 


\section{Introduction}

To provide effective support services to athletes, sports science and medicine practitioners must understand the physical demands of the activity [1]. The acute activity demands of ballet have been relatively well described; ballet is intermittent [2], with an activity profile comparable to team and racquet sports $[3,4]$. Performances are comprised of short durations of high-intensity movement interspersed with periods of low-intensity activity, during which a dancer may be in character or off-stage [5]. Within a performance, dancers are required to execute highly technical jumps, lifts, and balances, requiring strength, power, flexibility, and motor control [6]. The demands of a ballet schedule over weeks, months, and years, however, have not yet been explored.

To date, no study has investigated the rehearsal or performance schedules of a professional ballet company beyond a three-week period. Several studies report superficial descriptive data regarding the structure of a ballet schedule: companies perform $\sim 145$ shows per season, comprised of $\sim 15$ different productions, and weekly dance hours are between 30-40 h [7]. It is unclear, however, in how many of these shows individual dancers perform, in how many of the productions individual dancers are cast, and how much intra-individual, inter-individual, and seasonal variation in dance hours exists. Furthermore, no study has investigated the rehearsal periods required to stage specific productions, nor the factors which may influence these rehearsal periods.

Several position stands and consensus statements have been published relating to longitudinal workload in sport, and its relationships with performance, overtraining, injury, and illness [8, 9]. Despite suggestions that ballet, like sport, should embrace established training principles [10, 11] the absence of published longitudinal data relating to the structure of a ballet season makes it challenging to implement periodization strategies. In the present study we explore a five-year data set of the ballet class, rehearsal, and performance exposure scheduled by an elite professional ballet company. Measures of exposure, although lacking a measure of intensity, have been shown to be important variables to monitor in sport $[12,13,14]$, whilst excessive week-to-week changes in dance exposure have been associated with injury risk in professional ballet [15]. Furthermore, although data describing both the volume and intensity of activity are commonplace in sporting research, this level of data is not yet routinely collected in professional ballet companies due to the large number of dancer, limited resources, cultural challenges, and individualized schedules. The present data therefore represents a considerable progression in the quality of longitudinal data in this field.

The first aim was to describe the structural characteristics of a professional ballet season; namely, rehearsal hours and performance counts, intra-season variation, and repertoire make-up. The second aim was to identify factors related to the variation in rehearsal hours across different productions.

\section{Methods}

\subsection{Participants}

The initial sample were 124 dancers of The Royal Ballet; 108 gave written informed consent. A further 16 dancers were contacted: one declined to participate, and 15 did not respond. A legitimate interest assessment was completed, following which written support from both the Data Controller and Clinical Director of the company was provided to use anonymized data pertaining to 15 participants who could not be contacted. This was approved by the local ethics committee in accordance with the Declaration of Helsinki. A total of 123 dancers (women: $n=66,28.0 \pm 8.3 \mathrm{y}$; men: $n=57,27.9 \pm 8.5$ y) were therefore included in this study.

All company members are assigned a rank. The rank of apprentice indicates the dancer is in their first year of professional ballet. Dancers may then be promoted through the ranks of artist, first artist, 
Table 1: Company demographics for each season. Numbers in brackets indicate the count of dancers who were not included in the study.

\begin{tabular}{lccccc}
\hline Demographic & $2015 / 16$ & $2016 / 17$ & $2017 / 18$ & $2018 / 19$ & $2019 / 20$ \\
\hline All & 88 & 91 & 90 & 99 & 99 \\
Female & & & & & \\
$\quad$ Apprentice & 2 & 4 & 3 & 4 & 4 \\
$\quad$ Artist & 11 & 11 & 10 & 14 & 12 \\
First Artist & 9 & 10 & 11 & 10 & 12 \\
$\quad$ Soloist & 11 & 9 & 8 & 4 & 5 \\
First Soloist & 7 & 7 & 6 & 9 & 9 \\
Principal & 6 & 8 & 8 & 8 & 8 \\
P.C. ArtistA & 2 & 1 & 3 & 3 & 3 \\
Male & & & & & \\
Apprentice & 3 & 4 & 4 & 4 & 2 \\
Artist & 7 & 7 & 7 & 10 & 11 \\
First Artist & 5 & 6 & 6 & 7 & 7 \\
Soloist & $8(1)$ & $7(1)$ & 7 & 7 & 8 \\
First Soloist & 7 & 5 & 4 & 5 & 5 \\
Principal & 7 & 9 & 8 & 9 & 8 \\
P.C. Artist & 3 & 3 & 5 & 5 & 5 \\
\hline
\end{tabular}

P.C. Artist - Principal Character Artist

soloist, first soloist, and principal, performing increasingly featured roles as their seniority increases. One additional rank, principal character artist, is given to older company members who perform less physically demanding character roles. A breakdown of the distribution of company ranks across each of the five seasons is presented in Table 1.

\subsection{Design}

We used a descriptive cohort design to explore the structure of a professional ballet season, using data collected for a larger prospective study [16]. Ballet classes, rehearsals and performances taking place at the Royal Opera House, London, were prospectively recorded as part of normal working practices between the 2015-16 and 2019-20 seasons.

\subsection{Data Collection}

Three session types were included in this study: Class - typically the first session of a dancer's day, focusing on ballet technique; Rehearsal - a session during which dancers will be learning or practicing choreography for a specific ballet; and Performance - a single show on the main stage for which a public audience is present. Throughout this study the term Production is also used, referring to the ballet being performed (e.g., Romeo and Juliet, The Nutcracker, etc.). Class and rehearsal data were recorded by the company's Artistic Scheduling Manager. Data were entered once a week using a bespoke athlete management system (Smartabase, Fusion Sport, Brisbane, Australia). Performance data were recorded using casting sheets; both electronic and hard copies were filed following each performance. Scheduling data for touring periods were incomplete, and were therefore excluded from this study. Touring periods were typically 4 weeks in duration during June and July, immediately 
following the conclusion of the 2015-16 to 2018-19 seasons.

Throughout the data collection period, time-loss injury data were recorded to the athlete management system by in-house Chartered Physiotherapists. A time-loss injury was defined as "any injury that prevented a dancer from taking a full part in all dance-related activities that would normally be required of them for a period equal to or greater than 24 hours after the injury was sustained" [7]. For analyses of weekly ballet exposure, data points were removed from the analysis when the dancer was designated as injured for more than two days in the week (1,767 out of 15,837 dancer-weeks). For counts of performances per season data points were removed from the analysis when the dancer was designated as injured for more than $10 \%$ of days during the season (98 out of 365 dancer-seasons). These decisions were made such that data reflected the demands of an uninjured dancer's schedule.

\subsection{Data Processing}

Following the conclusion of the 2019-20 season, all scheduled class and rehearsal data between $4^{\text {th }}$ August 2015 and $15^{\text {th }}$ March 2020 were exported from the athlete management system. Performance involvements were determined by manual inspection of hard copies of casting sheets, ensuring all lastminute casting changes were accounted for. Neither electronic nor hard copies of casting sheets were available for 8 performances (1.2\% of all performances). No action was taken to impute data.

Scheduling data were used to calculate the following variables: weekly dance hours - the sum of dance hours in each dancer-week; seasonal performance count - the count of performances in each dancer-season; week-to-week change - each individual's change in weekly dance hours from the previous week; individual rehearsal hours - the rehearsal hours completed by each dancer in preparation for a specific production; company rehearsal hours - the total rehearsal hours completed by all dancers in preparation for a specific production (i.e., the sum of dancers' individual rehearsal hours); and production time-efficiency - the ratio of company rehearsal hours to the total on-stage performance time resulting from the production (i.e., company rehearsal hours / [number of performances $\times$ performance duration]). For seasonal performance counts, data from the 2019-20 season were excluded from the analysis due to being cut short as a result of the COVID-19 global pandemic.

\subsection{Statistical Analysis}

To investigate differences in weekly dance hours across sexes, company ranks, and months, and differences in seasonal performance counts across sexes and company ranks, linear mixed effects models were implemented using the lme $4 \mathrm{R}$ package [17]. Sex, company rank, and month were entered as fixed effects, whilst participant identity and season were entered as random effects. Prior to further analyses, the models' assumptions of normality, linearity, and homoscedasticity were confirmed. Bonferroni adjusted pairwise comparisons of estimated marginal means were used to compare differences across sex, rank, and month. Significance was accepted at $p<.025$, accounting for two primary outcomes.

A mixed effects random forest regression model implemented with the MixRF R package [18] was used to determine associations between individual rehearsal hours and a series of dancer (company rank, sex, performance count) and performance characteristics (production running time, years since last staged, existing ballet or newly created choreography). Random forests have previously been shown to produce better predictive accuracy than linear models, handle large data sets well, and account for non-linearity. Furthermore, random forests enable the calculation of Shapley additive explanations [19], whereby a portion of the target variable is attributed to each predictor; in this instance, the number of rehearsal hours attributed to each predictor. Leave-one-season-out cross validation was used to assess model performance. Five models were constructed, each trained on four seasons of data, and evaluated using the final season. A random sample of $10 \%$ of the data $(n=294)$ was excluded 

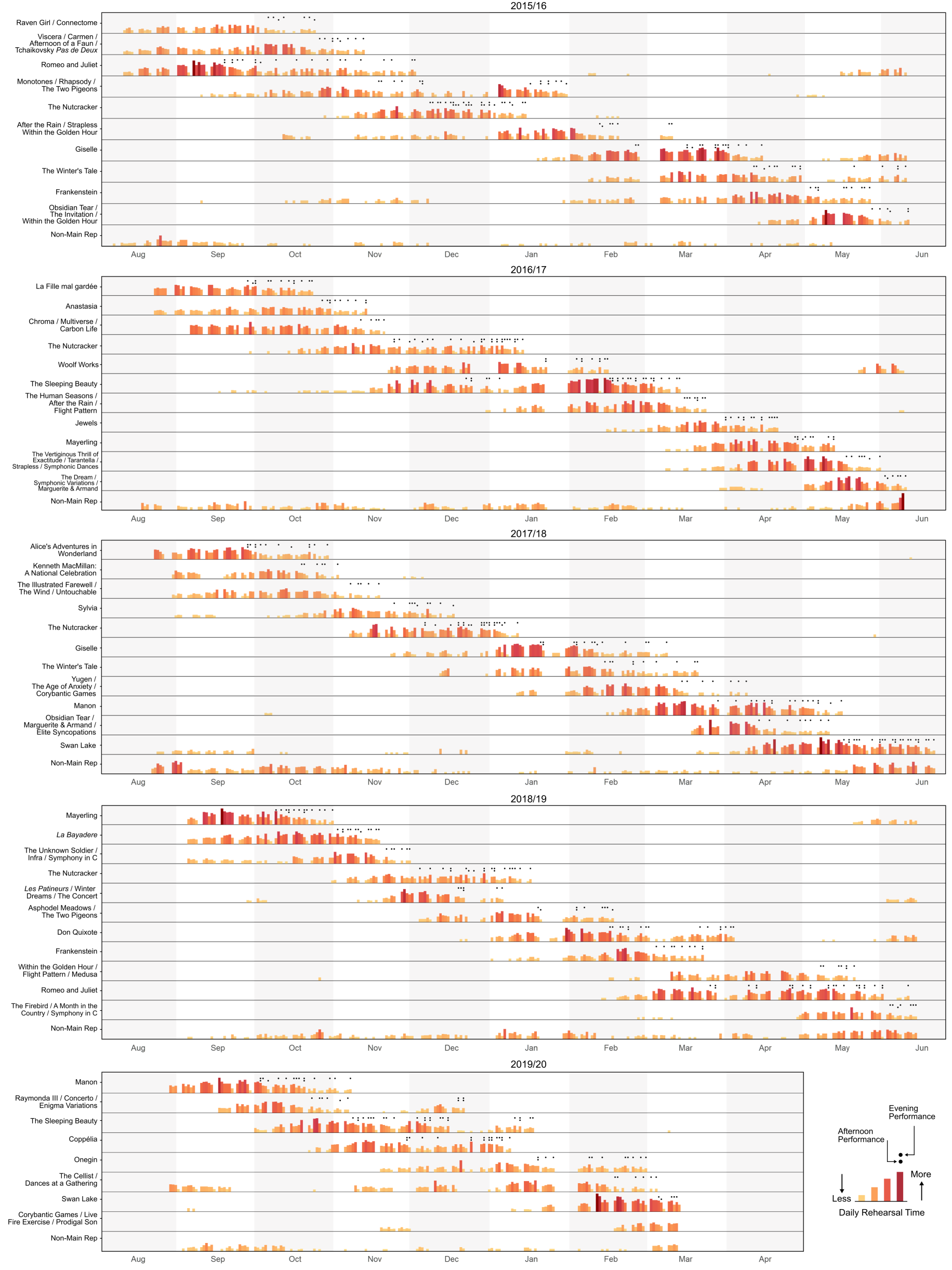

Figure 1: Timelines of each included season, illustrating the distribution of rehearsal and performance hours across the repertoire. Column height and darkness represent the daily rehearsal time for the production, whilst lower and upper dots indicate matinees and evening performances, respectively. The end of the season was immediately followed by a four-week touring period. 
from the testing set and used to tune parameters of the first model (mtry $=3$, ntree $=500$ ), which were used for subsequent models. Model performance was evaluated via the mean root-mean-square-error, and the strength of the relationship between the predicted and observed values. Shapley additive explanations were calculated using the shapper $\mathrm{R}$ package [20]. Data are reported as mean $\pm \mathrm{SD}$. Data processing and analyses were conducted using R v.4.0.3 (R Foundation for Statistical Computing, Vienna, Austria).

\section{Results}

All seasons ran from August to June, except for 2019-20 which concluded prematurely in March due to the COVID-19 global pandemic. Touring periods immediately followed the final week of each season (mean duration $28 \pm 4$ days). Timelines of the repertoire in each season are shown in Figure 1 . The company staged $10.5 \pm 0.8$ (range: 9-11) productions per season, comprised of $18.3 \pm 1.6$ (range: 16-20) separate ballets. The company performed totals of $133,135,138,132$, and 94 (+43 cancelled) shows in the 2015-16 to 2019-20 seasons, respectively.

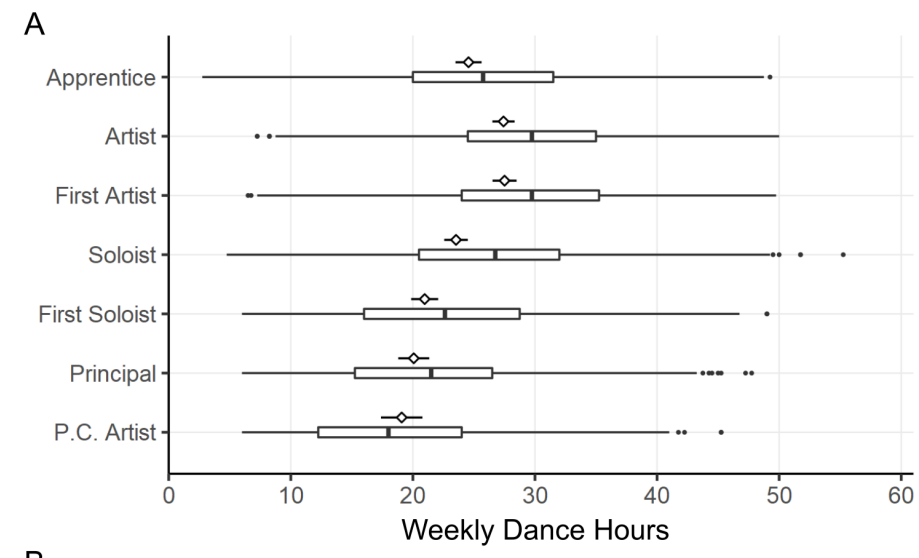

B
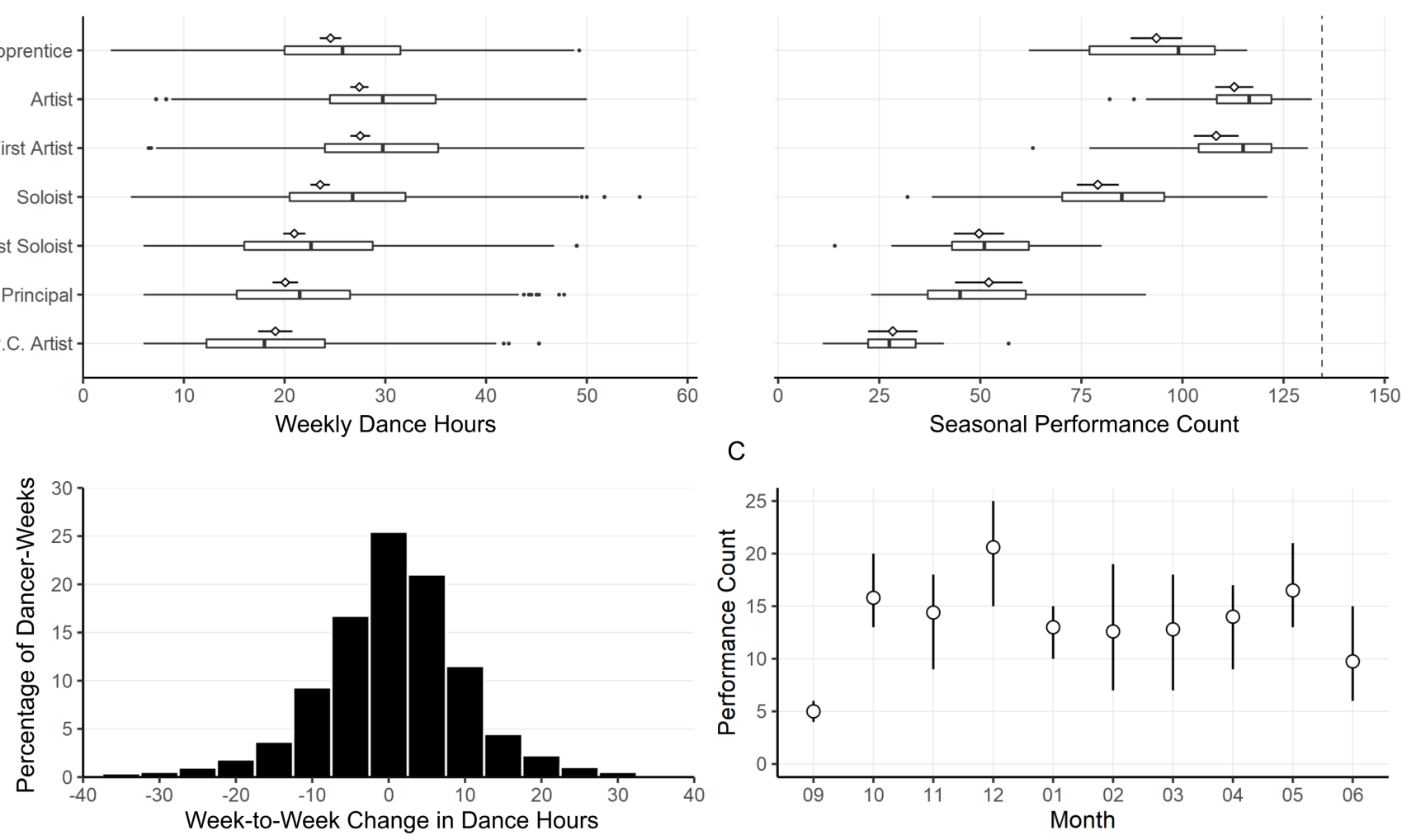

C

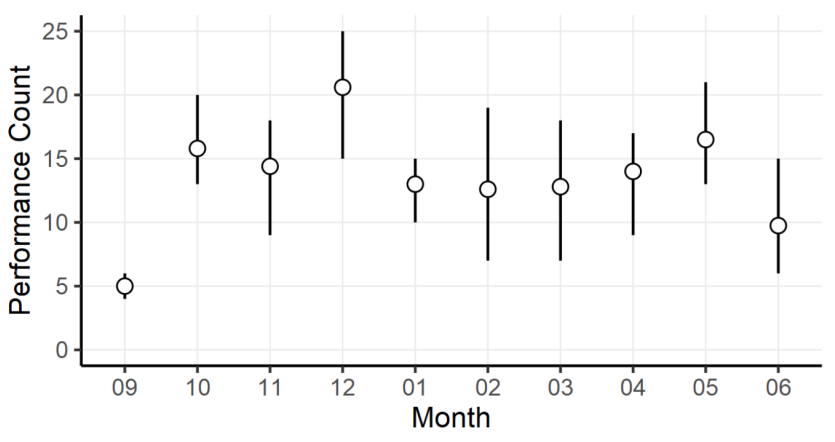

Figure 2: A) Distributions of weekly dance hours and seasonal performance counts, by company rank. Diamonds and bars indicate the estimated marginal mean and $95 \%$ confidence intervals extracted from mixed effects models. The dotted line indicates the mean number of total company performances during the study period. B) The distribution of week-to-week changes in dance hours across the five seasons. C) Mean count of performances in each month across the five seasons. Bars represent the range in observed counts. P.C. Artist-Principal Character Artist.

The mixed effects model investigating weekly dance hours revealed significant main effects of company rank $(p<.001$; Figure $2-\mathrm{A})$, month $(p<.001)$, and company rank $\times$ month interaction $(p<$ .001; Figure 3), but no effect of sex (female 22.8 h, $95 \%$ CI [22.0, 23.6]; male 23.9 h, $95 \%$ CI [23.1, $24.7] ; p=.049)$ or sex $\times$ company rank interaction $(p=.348)$. The mixed effects model investigating seasonal show count revealed a significant main effect of company rank $(p<.001$; Figure 2-A), but 


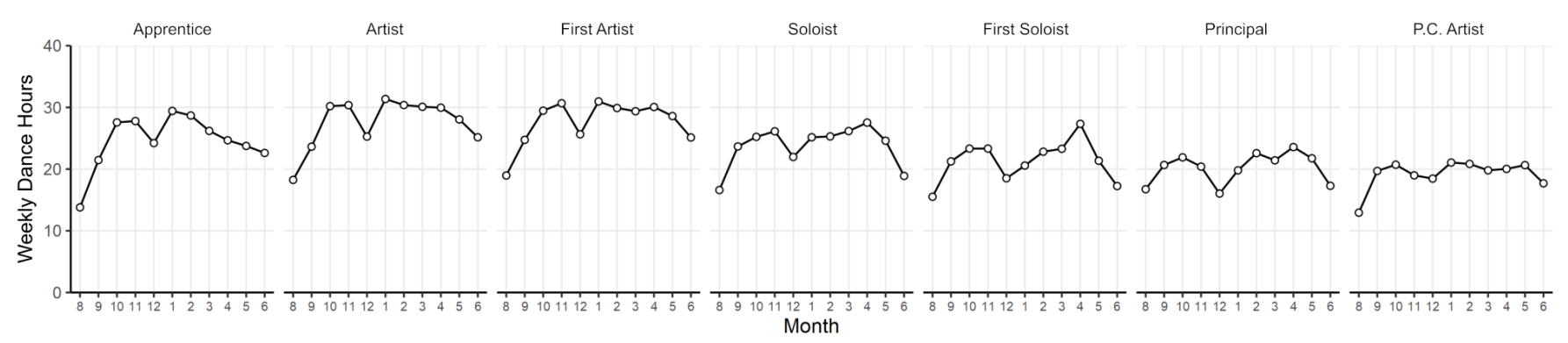

Figure 3: Mixed effects model derived estimated marginal mean weekly dance hours for each company rank $\times$ month combination. P.C. Artist-Principal Character Artist.

no effect of sex (female 73.5 shows, $95 \%$ CI $[69.5,77.4]$; male 76.2 shows, $95 \%$ CI $[72.3,80.1] ; p=$ $.338)$, or sex $\times$ company rank interaction $(p=.689)$. Plots depicting the distribution of week-to-week changes in exposure across all seasons and performance density across each season are presented in Figures 2-B and 2-C, respectively.

The individual rehearsal hours, company rehearsal hours, and production time-efficiency for all productions staged across the five seasons are presented in Supplementary Material 1. The cross validation of random forest models revealed a mean root-mean-square-error of $17.8 \mathrm{~h}$ (equating to $40 \%$ of the mean individual rehearsal hours), whilst the $\mathrm{r}^{2}$ for the relationship between predicted and observed individual rehearsal hours was 0.52 . The attribution of rehearsal hours to each predictor variable is shown in Figure 4.

\section{Discussion}

This study explored five years of rehearsal and performance scheduling data at a professional ballet company; this is the first study investigating the longitudinal working demands of a professional ballet company for a period beyond three weeks. Mean weekly dance hours were between 19.1 and $27.5 \mathrm{~h}$, though weeks involving $>40 \mathrm{~h}$ of scheduled dance were common; large variations in weekly dance hours were evident both between and within company rank and month of the season. The present results provide data facilitating the periodization of rehearsal and performance volume throughout a ballet season. Firstly, dancer and rehearsal characteristics known in advance of a rehearsal period explained over half of the variance in the duration of rehearsal required to stage a production. Secondly, we provide individual and company rehearsal durations for specific productions, and the time-efficiency of those productions. Dancers involved in creating leading roles within new ballets appear to complete considerably more rehearsal than they might in an existing work, warranting offload from other productions. These results are the first to investigate the structure of a ballet season, and may be useful for staff when periodizing repertoire, casting productions, or planning late-stage rehabilitation for dancers following injury.

We observed mean weekly dance hours between 19.1 and $27.5 \mathrm{~h}$, exceeding training and competition durations reported in elite rowing [21], rugby union [22], and track and field [23]. Whilst it is important to acknowledge that exposure time is not a comprehensive measure of training load, the extent to which these values exceed those in sporting contexts is notable, and likely underpins the reduction in physical performance measures observed at the conclusion of a ballet season [10]. Large variation in weekly dance hours was evident across the cohort; the 'worst-case-scenario' [24] for a dancer may therefore be $\sim 50 \mathrm{~h}$ of scheduled dance in a week. In a rehabilitation context, medical staff should consider whether a dancer is prepared to tolerate this volume of work before returning to full rehearsal. In the present 


\begin{tabular}{|c|c|c|c|c|c|c|c|c|c|c|c|c|}
\hline Production & New & Season & $\begin{array}{c}\text { Duration } \\
\text { (mins) }\end{array}$ & $\begin{array}{l}\text { Cast } \\
\text { Size }\end{array}$ & $\begin{array}{c}n \\
\text { Shows }\end{array}$ & & $\begin{array}{r}\text { ompany } R \\
\text { Hou }\end{array}$ & $\begin{array}{l}\text { ehearsal } \\
\text { s }\end{array}$ & & Individua & $\begin{array}{l}\text { Rehe } \\
\text { irs }\end{array}$ & earsal \\
\hline & & & & & & 0 & 2500500 & 75001000 & 0 & 100 & 15 & \\
\hline Swan Lake & - & $2017 / 18$ & 120 & 72 & 24 & & & & & $\longrightarrow$ & ב- & — \\
\hline & 0 & $2019 / 20$ & & 64 & 5 & - & a & & $\longrightarrow$ & ב- & & \\
\hline Frankenstein & - & $2015 / 16$ & 125 & 62 & 10 & E & & 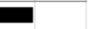 & . & $\longrightarrow$ & 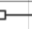 & - \\
\hline & 0 & $2018 / 19$ & & 50 & 9 & & & & - $\rightarrow$ & -匹-・ & & \\
\hline The Sleeping Beauty & 0 & 2016/17 & 134 & 74 & 25 & & & & $\rightarrow$ & $-\infty-\infty$ & & \\
\hline & 0 & $2019 / 20$ & & 78 & 24 & - & & & $-\infty$ & - $\cdots$ & & \\
\hline Don Quixote & 0 & $2018 / 19$ & 125 & 68 & 13 & E & ( & & 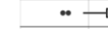 & $-\square-$. & & \\
\hline Mayerling & 0 & $2016 / 17$ & 132 & 77 & 10 & E & ש & & - & 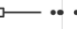 & & \\
\hline & 0 & $2018 / 19$ & & 77 & 14 & & & & $-\infty$ & 드 & & \\
\hline Anastasia & 0 & $2016 / 17$ & 110 & 71 & 10 & $\bar{E}$ & & & - $\rightarrow$ & $-\square-$ & & \\
\hline Alice's Adventures in... & 0 & 2017/18 & 117 & 70 & 13 & E & G & & $\boldsymbol{\cdots} \quad-5$ & - & & \\
\hline La Bayadère & 0 & $2018 / 19$ & 118 & 74 & 12 & E & & & 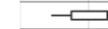 & - & & \\
\hline The Cellist & - & $2019 / 20$ & 65 & 39 & 6 & & a & & - & $-\square$ & - & $\cdots$ \\
\hline Romeo and Juliet & 0 & 2015/16 & 136 & 74 & 20 & & & & - & ב- - & & \\
\hline & 0 & $2018 / 19$ & & 78 & 26 & & & & - $-\square$ & - $\cdots$ & & \\
\hline The Winter's Tale & 0 & 2015/16 & 107 & 62 & 15 & E & a & & $\cdot \cdot \cdot-\square$ & $-\infty$ & & \\
\hline & 0 & $2017 / 18$ & & 65 & 10 & - & a & & . • 一 & 口- & & \\
\hline Manon & 0 & 2017/18 & 115 & 73 & 14 & - & ש & & 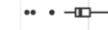 & $\cdots \cdots$ & & \\
\hline & 0 & $2019 / 20$ & & 79 & 15 & & & & $-\infty$ & $-\cdot$ & & \\
\hline The Two Pigeons & 0 & $2015 / 16$ & 70 & 61 & 15 & & 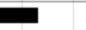 & & 一品 & 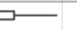 & & \\
\hline & 0 & $2018 / 19$ & & 65 & 9 & - & & & $\cdot-\mathbb{w}-$. & & & \\
\hline Coppelia & 0 & $2019 / 20$ & 95 & 69 & 18 & E & C & & - - & - & & \\
\hline Flight Pattern & $\bullet$ & $2016 / 17$ & 30 & 37 & 8 & & & & • $\quad \cdots$ & $\square$ & & \\
\hline & 0 & $2018 / 19$ & & 40 & 7 & - & & & $-\mathbb{t}$ & & & \\
\hline Onegin & 0 & $2019 / 20$ & 93 & 57 & 12 & E & ב & & $\because$ & $-\infty$ & & \\
\hline Jewels & 0 & $2016 / 17$ & 90 & 63 & 14 & E & 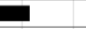 & & -בד- & {[} & & \\
\hline Giselle & 0 & $2015 / 16$ & 103 & 55 & 17 & E & & & 一匹- & $\cdots$ & & \\
\hline & 0 & 2017/18 & & 69 & 14 & & & & $\rightarrow \square-$ & —. & & \\
\hline Sylvia & 0 & 2017/18 & 91 & 64 & 9 & E & & & $-\infty$ & & & \\
\hline The Nutcracker & 0 & 2015/16 & 99 & 72 & 27 & $=$ & & & $-\square-$ & & & \\
\hline & 0 & $2016 / 17$ & & 79 & 27 & & & & •—- & & & \\
\hline & 0 & 2017/18 & & 71 & 24 & & ש & & - $-\infty-$ & & & \\
\hline & 0 & $2018 / 19$ & & 70 & 19 & - & & & $\because \square-$. & & & \\
\hline Elite Syncopations & 0 & $2017 / 18$ & 36 & 61 & 11 & E & & & œ—- & & & \\
\hline La Fille mal gardée & 0 & $2016 / 17$ & 105 & 58 & 13 & E & & & $-\varpi$ & $-\cdot \cdot$ & & \\
\hline Woolf Works & 0 & $2016 / 17$ & 95 & 44 & 10 & E & & & - 口 & 己- & & \\
\hline Carmen & - & $2015 / 16$ & 59 & 42 & 9 & - & & & $\rightarrow$ & [ـ- & & \\
\hline Symphony in C & 0 & $2018 / 19$ & 36 & 66 & 12 & 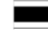 & & & ¿匹- & & & \\
\hline The Unknown Soldier & - & $2018 / 19$ & 30 & 39 & 6 & - & & & $\cdots-\mathbb{a} \cdot$ & & & \\
\hline Symphonic Dances & - & 2016/17 & 45 & 35 & 7 & - & & & $-\infty$ & - & & \\
\hline Strapless & - & $2015 / 16$ & 40 & 40 & 7 & E & & & $\square \square$ & -・ & & \\
\hline & 0 & $2016 / 17$ & & 40 & 7 & [ & & & $\infty-\ldots$ & & & \\
\hline Raymonda & 0 & $2019 / 20$ & 34 & 69 & 10 & $\square$ & & & - at & & & \\
\hline Corybantic Games & - & $2017 / 18$ & 33 & 25 & 7 & - & & & 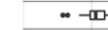 & & & \\
\hline Multiverse & - & $2016 / 17$ & 35 & 27 & 5 & - & & & $\cdot-\infty$ & & & \\
\hline Concerto & 0 & $2019 / 20$ & 25 & 66 & 10 & a & & & 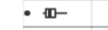 & & & \\
\hline The Firebird & 0 & $2018 / 19$ & 47 & 62 & 7 & a & & & $\rightarrow$ - & & & \\
\hline Raven Girl & 0 & $2015 / 16$ & 75 & 34 & 7 & 口 & & & $\cdot-a-$ & - & & \\
\hline The Dream & 0 & $2016 / 17$ & 52 & 56 & 6 & 口 & & & $-a \rightarrow$ & & & \\
\hline Medusa & - & $2018 / 19$ & 40 & 23 & 7 & 口 & & & $-\infty-$ & - - & & \\
\hline The Wind & - & $2017 / 18$ & 37 & 27 & 5 & - & & & $-\infty-$ & $\cdots$ & & \\
\hline Obsidian Tear & - & 2015/16 & 29 & 17 & 6 & 口 & & & & $\square$ & & \\
\hline & 0 & $2017 / 18$ & & 18 & 7 & 【 & & & $-\varpi-$ & & & \\
\hline Within the Golden Hour & 0 & $2015 / 16$ & 35 & 38 & 13 & I & & & 口 & & & \\
\hline & 0 & $2018 / 19$ & & 37 & 7 & [ & & & $+\infty$ & & & \\
\hline Carbon Life & 0 & $2016 / 17$ & 40 & 29 & 5 & - & & & - $-\mathbb{1}$ & & & \\
\hline Enigma Variations & 0 & $2019 / 20$ & 34 & 56 & 10 & 口 & & & 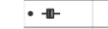 & & & \\
\hline Asphodel Meadows & 0 & $2018 / 19$ & 25 & 42 & 7 & - & & & $-a$ & & & \\
\hline Untouchable & 0 & 2017/18 & 30 & 24 & 5 & - & & & $\cdot-\boldsymbol{a r}$ & & & \\
\hline The Invitation & 0 & $2015 / 16$ & 60 & 44 & 6 & - & & & 口- & & & \\
\hline Yugen & - & $2017 / 18$ & 19 & 28 & 7 & - & & & $\rightarrow$ 므- & & & \\
\hline Dances at a Gathering & 0 & $2019 / 20$ & 63 & 24 & 6 & $\overline{\mathbf{D}}$ & & & 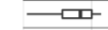 & & & \\
\hline The Human Seasons & 0 & $2016 / 17$ & 35 & 26 & 7 & - & & & $-\mathbb{w}$. & & & \\
\hline Winter Dreams & 0 & $2018 / 19$ & 52 & 32 & 6 & $\overline{\mathbf{D}}$ & & & $\Phi-$ & & & \\
\hline The Judas Tree & 0 & 2017/18 & 36 & 29 & 4 & [ & & & $\cdots+\cdots$ & & & \\
\hline The Concert & 0 & $2018 / 19$ & 29 & 33 & 6 & [ & & & a- & & & \\
\hline Viscera & 0 & $2015 / 16$ & 23 & 36 & 9 & घ & & & $-\square-$ & & & \\
\hline Infra & 0 & $2018 / 19$ & 29 & 24 & 6 & घ & & & $=-\mathbb{- 1} \cdot$ & & & \\
\hline Les Patineurs & 0 & $2018 / 19$ & 25 & 35 & 6 & - & & & + & & & \\
\hline After the Rain & 0 & $2015 / 16$ & 20 & 18 & 7 & घ & & & $\rightarrow$ & & & \\
\hline & 0 & $2016 / 17$ & & 15 & 8 & I & & & -10 & & & \\
\hline A Month in the Country & 0 & $2018 / 19$ & 45 & 21 & 6 & I & & & $-\mathbb{w}-\cdot$ & & & \\
\hline Rhapsody & 0 & 2015/16 & 27 & 33 & 8 & I & & & 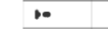 & & & \\
\hline Connectome & 0 & $2015 / 16$ & 32 & 16 & 7 & I & & & थ.+. & & & \\
\hline Marguerite \& Armand & 0 & $2016 / 17$ & 34 & 32 & 6 & I & & & I m. & & & \\
\hline & 0 & $2017 / 18$ & & 23 & 7 & I & & & $0--$ & & & \\
\hline Symphonic Variations & 0 & $2016 / 17$ & 20 & 15 & 6 & I & & & - ar & & & \\
\hline The Age of Anxiety & 0 & $2017 / 18$ & 39 & 13 & 7 & I & & & $\square$ & & & \\
\hline Chroma & 0 & $2016 / 17$ & 25 & 12 & 5 & I & & & at & & & \\
\hline Monotones & 0 & $2015 / 16$ & 21 & 23 & 7 & I & & & D & & & \\
\hline & 0 & $2019 / 20$ & & 6 & 2 & 1 & & & I & & & \\
\hline Tarantella & 0 & 2016/17 & 10 & 6 & 7 & 1 & & & I & & & \\
\hline Tchaikovsky pas de deux & 0 & $2015 / 16$ & 11 & 5 & 9 & I & & & I & & & \\
\hline Afternoon of a Faun & 0 & 2015/16 & 11 & 6 & 9 & 1 & & & - & & & \\
\hline
\end{tabular}

Figure 4: Rehearsal characteristics for each production staged. Multiple rows are given for productions which have been performed in multiple seasons. Filled circles indicate new works created on the company, whereas open circles represent existing works. 


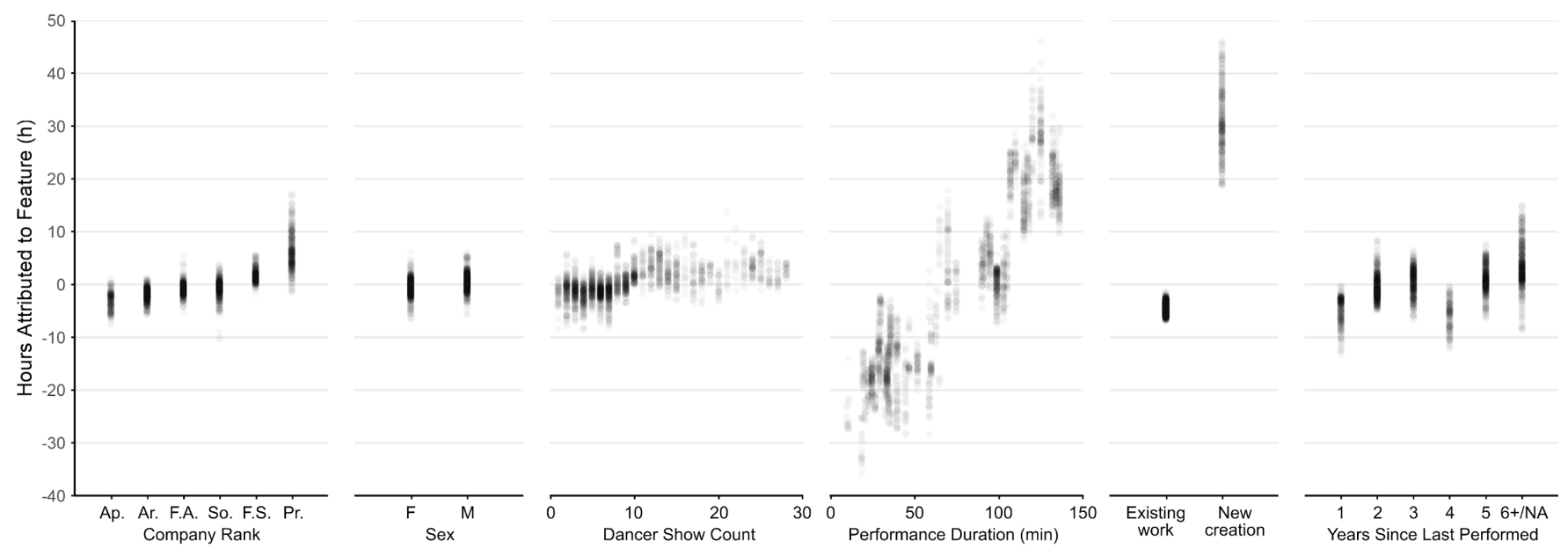

Figure 5: The number of rehearsal hours attributed to each random forest predictor variable, calculated using Shapley additive explanations. Each point represents the prediction of a dancer's rehearsal hours for a single production. A positive y-axis value indicates that the variable was attributed with increasing that individual's rehearsal hours, whilst a negative value indicates the variable was attributed with a reduction in rehearsal hours. Values of greater magnitude are indicative of more important predictor variables. Ap. - Apprentice; Ar. - Artist; F.A. - First Artist; So. - Soloist; F.S. - First Soloist; Pr. - Principal.

cohort, we have previously demonstrated increases in injury risk with greater progressions in training volume $[25,26]$. The frequency of large week-to-week increases in dance hours should therefore be a cause for concern; this is particularly the case as we believe it would be unlikely for intensity to be adjusted in response to increases in exposure. In keeping with well-established principles of training, ballet companies should avoid scheduling large spikes in rehearsal and performance volume where possible.

We observed large variations in weekly dance hours both within, and between company ranks. An incremental increase in weekly dance hours was observed from apprentice to artist and first artist, following which weekly dance hours decreased through the ranks of soloist, first soloist, principal, and principal character artist. Junior company members, however, have previously been shown to spend less time active across the day compared with soloists and principals [27]. Thus, it seems probable that as a dancer's rank increases, their volume of work decreases whilst the intensity of their work increases [5]. The transition from pre-professional to professional ballet has been identified as a potential period of heightened injury risk due to increased ballet exposure [28]. However, we observed similar weekly dance hours in apprentices as those previously reported in pre-professional dancers [29]. suggesting this transition does not represent an increase in dance exposure. No difference in dance hours was observed between males and females. Scheduled dance time therefore appears to be broadly comparable between male and female dancers, though in specific companies, and at specific timepoints, these values are likely to fluctuate based on the repertoire, casting, and company demographic.

Ballet exposure and performance frequency fluctuated across the course of each season. The relatively low dance exposure recorded in August and September reflect the absence of performances, as well as efforts to incrementally increase load in response to research identifying this period as one of heightened injury risk [30]. Despite being the peak in performance congestion, December nonetheless sees a reduction in dance hours across all company ranks. This reflects the staging of The Nutcracker in four of the five seasons, a production which is highly time-efficient. Thus, a regular and well-established ballet requiring relatively little rehearsal, in combination with a long performance run, may be a useful tool by which to de-load rehearsal volume. January to April demonstrated a sustained peak in dance time, however, periods of performance congestion were inconsistent across the five seasons. 
For the first time, we have investigated the duration of rehearsal completed in preparation for individual productions, and explored factors contributing to the variation in these durations. The individual rehearsal hours predicted by the random forest model explained $52 \%$ of the variance in the actual data; whilst this degree of accuracy does not justify the modelling of individual rehearsal durations in practice, several predictors show relationships which may guide casting or repertoire decisions. Whilst it is unsurprising that greater rehearsal hours were observed in preparation for longer productions, full length productions were nonetheless time-efficient to stage, primarily due to the large number of performances of those productions. Newly created ballets were typically the least time-efficient to stage, reflecting the additional time required to choreograph and subsequently learn the production. It is evident from the individual rehearsal hours completed in preparation for a newly created ballet that individuals involved in the creation of a leading role complete considerably more rehearsal. Consideration should be given to the concurrent roles in which these dancers are cast; where possible, companies should consider offloading other roles to ensure their work is manageable. Finally, more senior ranking dancers typically complete greater rehearsal hours than lower-ranking dancers for individual productions; their lower weekly ballet exposure is therefore a result of being cast in fewer productions.

\subsection{Practical Applications}

In line with previous recommendations, the present results provide a basis for the periodization of rehearsal and performance volume throughout a professional ballet season [11]. For example, specific applications of these results include: providing periods of volume offload by scheduling time-efficient productions amongst inefficient ones; forecasting the required rehearsal hours of a production to facilitate a gradual progression in ballet volume in advance of the start of rehearsals; planning an incremental return-to-dance during rehabilitation; and periodization of the repertoire to avoid periods of rehearsal and performance congestion.

Several specific ballets warrant discussion. Firstly, full-length classical ballets such as The Nutcracker, Romeo and Juliet, Manon and The Sleeping Beauty were highly time-efficient to stage due to their long performance runs, and frequent appearances season-to-season. To this end, even full-length new creations such as Swan Lake and Frankenstein, which incurred by far the largest company rehearsal hours, were relatively time-efficient to stage because of their long performance runs. Mixed bills comprised of several shorter ballets typically required the most rehearsal hours relative to the resulting performance time. In the instance that one of those shorter ballets is a new creation, an effort should be made to account for the resulting increase in rehearsal volume by pairing it with more time-efficient productions.

\subsection{Strengths and Limitations}

Strengths of this study include the five-year dataset; the entry of all class and rehearsal sessions by a single individual; the use of a standardized entry form to record class and rehearsal data; and the high availability of casting sheets. Several limitations of the data should be acknowledged. Firstly, the study is limited by a lack of an intensity measure, therefore we cannot fully understand workload across this period. There was also no register of attendance taken at rehearsals - we believe it is unlikely though, that dancers would not have attended rehearsals for which they were scheduled. It was beyond the scope of the available data to break down every individual performance role across the study period. We therefore could not ascertain a dancer's level of involvement within a show, or within specific productions in a mixed bill. It is important to note that differences exist between companies in the rehearsal and performance schedule structure, and the casting of productions. Science and medicine 
practitioners working in professional ballet should therefore consider the degree of similarity between companies when applying these results.

\section{Conclusion}

This study investigated the class, rehearsal, and performance schedules of a professional ballet company over five years. Through repertoire planning, casting decisions, and the manipulation of rehearsal schedules, professional ballet companies can periodize rehearsal and performance volume across a season. Artistic staff and athletic trainers should be mindful of the high volumes of work associated with new productions, large week-to-week variability in dance hours, and congested periods of dance exposure in the latter stages of the season. The present results may be used to inform the periodization of a ballet season, and provide practical data with which to manipulate rehearsal and performance volume.

\section{Contributions}

Contributed to conception and design: JS, AM, DB, SW, MS, CP, JT Contributed to acquisition of data: JS, AM Contributed to analysis and interpretation of data: JS, SW Drafted and/or revised the article: JS, AM, DB, SW, MS, CP, JT Approved the submitted version for publication: JS, AM, DB, $\mathrm{SW}, \mathrm{MS}, \mathrm{CP}, \mathrm{JT}$

\section{Acknowledgements}

We would like to thank the staff and artists of The Royal Ballet for their assistance during this project. In particular, we are indebted to The Royal Ballet's Artistic Scheduling Manager, Philip Mosley, for recording the scheduling data and providing the casting sheets used in this study.

\section{Funding Information}

Joseph Shaw received PhD funding from The Royal Ballet via St. Mary's University, Twickenham, for the completion of this research.

\section{$9 \quad$ Data and Supplementary Material}

Data are not available. There are no supplementary materials associated with this work.

\section{References}

[1] W. J. Kraemer, B. Comstock, J. E. Clark, and C. Dunn-Lewis. Athlete needs analysis. In Jay Hoffman, editor, NSCA's Guide to Program Design, chapter 1, pages 1-21. Human Kinetics, 1 edition, 2012.

[2] Jerald L. Cohen, Karen R. Segal, and William D. Mcardle. Heart Rate Response to Ballet Stage Performance. The Physician and Sportsmedicine, 10(11):120-133, 1982. ISSN 00913847. doi: 10.1080/00913847.1982.11947374. 
[3] Michael A. Christmass, Susan E. Richmond, Nigel T. Cable, Peter G. Arthur, and Peter E. Hartmann. Exercise intensity and metabolic response in singles tennis. Journal of Sports Sciences, 16(8):739-747, 1998. ISSN 02640414. doi: 10.1080/026404198366371.

[4] Aaron T. Scanlan, Ben J. Dascombe, Andrew P. Kidcaff, Jessica L. Peucker, and Vincent J. Dalbo. Gender-specific activity demands experienced during semiprofessional basketball game play. International Journal of Sports Physiology and Performance, 10(5):618-625, 2015. ISSN 15550265. doi: 10.1123/ijspp.2014-0407.

[5] MA Wyon, E Twitchett, Y Koutedakis, and Manuela Angioi. The day-to-day workload of ballet dancers. International Symposium on Performance Science, pages 143-148, 2011.

[6] E Twitchett, Yiannis Koutedakis, and MA Wyon. Physiological Fitness and Professional Classical Ballet Performance: a Brief Review. Journal of Strength and Conditioning Research, 23(9):27322740, 2009. ISSN 15334287. doi: 10.1519/JSC.0b013e3181bc1749.

[7] Nick Allen, Alan Nevill, John Brooks, Yiannis Koutedakis, and MA Wyon. Ballet Injuries: Injury Incidence and Severity Over 1 year. Journal of Orthopaedic 83 Sports Physical Therapy, 42(9): 781-790, 2012. ISSN 0190-6011. doi: 10.2519/jospt.2012.3893.

[8] Romain Meeusen, Martine Duclos, Carl Foster, Andrew Fry, Michael Gleeson, David Nieman, John Raglin, Gerard Rietjens, Jürgen Steinacker, and Axel Urhausen. Prevention, diagnosis and treatment of the overtraining syndrome: Joint consensus statement of the European College of Sport Science (ECSS) and the American College of Sports Medicine (ACSM). European Journal of Sport Science, 13(1):1-24, 2013. ISSN 17461391. doi: 10.1080/17461391.2012.730061.

[9] Torbjørn Soligard, Martin Schwellnus, Juan Manuel Alonso, Roald Bahr, Ben Clarsen, H. Paul Dijkstra, Tim Gabbett, Michael Gleeson, Martin Hägglund, Mark R. Hutchinson, Christa Janse Van Rensburg, Karim M. Khan, Romain Meeusen, John W. Orchard, Babette M. Pluim, Martin Raftery, Richard Budgett, and Lars Engebretsen. How much is too much? (Part 1) International Olympic Committee consensus statement on load in sport and risk of injury. British Journal of Sports Medicine, 50(17):1030-1041, 2016. ISSN 14730480. doi: 10.1136/bjsports-2016-096581.

[10] Y Koutedakis, L Myszkewycz, D Soulas, V Papapostolou, I Sullivan, and N C C Sharp. The Effects of Rest and Subsequent Training on Selected Physiological Parameters in Professional Female Classical Dancers. International Journal of Sports Medicine, 20(6):379-383, 1999.

[11] MA Wyon. Preparing to perform: periodization and dance. Journal of Dance Medicine $\mathcal{E}^{3}$ Science, 14(2):67-72, 2010. ISSN 1089313X.

[12] Asier Los Arcos, Raul Martínez-Santos, Javier Yanci, Jurdan Mendiguchia, and Alberto MéndezVillanueva. Negative Associations between Perceived Training Load, Volume and Changes in Physical Fitness in Professional Soccer Players Negative Associations between Perceived Training Load, Volume and Changes in Physical Fitness in Professional Soccer Players. Journal of Sports Science and Medicine, 14(2):394-401, 2015.

[13] Asier Los Arcos, Raúl Martínez-Santos, Yanci Javier, and Alberto Mendez-Villanueva. Monitoring Perceived Respiratory and Muscular Exertions and Physical Fitness in Young Professional Soccer Players During a 32-Week Period. Kinesiology, 49(2):153-160, 2017. doi: 10.26582/k.49.2.12. 
[14] Sean Williams, Grant Trewartha, Simon P.T. Kemp, John H.M. Brooks, Colin W. Fuller, Aileen E. Taylor, Matthew J. Cross, Gavin Shaddick, and Keith A. Stokes. How Much Rugby is Too Much? A Seven-Season Prospective Cohort Study of Match Exposure and Injury Risk in Professional Rugby Union Players. Sports Medicine, 47(11):2395-2402, 2017. ISSN 11792035. doi: 10.1007/ s40279-017-0721-3.

[15] Joseph W. Shaw, Adam M. Mattiussi, Derrick D. Brown, Sean Williams, Shane Kelly, Matthew Springham, Charles R. Pedlar, and Jamie Tallent. Dance Exposure, Individual Characteristics, and Injury Risk over Five Seasons in a Professional Ballet Company. Medicine \&6 Science in Sports $\&$ Exercise, 2021. doi: 10.1249/MSS.0000000000002725.

[16] Adam Mattiussi, Joseph W Shaw, Derrick D Brown, Phil Price, Daniel D Cohen, and Charles R Pedlar. Jumping in Ballet A Systematic Review of Kinetic and Kinematic Parameters. Medical Problems of Performing Artists, 36(2):108-128, 2021. doi: 10.21091/mppa.2021.2011.

[17] Douglas Bates, Martin Maechler, Ben Bolker, Steven Walker, Rune Haubo Bojesen Christensen, Henrik Singmann, Bin Dai, Fabian Scheipl, Gabor Grothendieck, Peter Green, and John Fox. Linear mixed-effects model using "Eigen" and S4. 2020. URL https://cran.r-project.org/ web/packages/lme4/lme4.pdf.

[18] Jiebiao Wang and Lin S Chen. A Random-Forest-Based Approach for Imputing Clustered Incomplete Data. 2016. doi: 10.1016/j.ajhg.2016.02.020. URL https://cran.r-project.org/web/ packages/MixRF/MixRF.pdf.

[19] Scott M. Lundberg and $\mathrm{Su}$ In Lee. A unified approach to interpreting model predictions. In Advances in Neural Information Processing Systems 30, pages 4768-4777, 2017.

[20] Szymon Maksymiuk, Alicja Gosiewska, Przemyslaw Biecek, Mateusz Staniak, and Michal Burdukiewicz. Wrapper of Python Library 'shap'. 2020. ISSN 10495258. URL https://cran. r-project.org/web/packages/shapper/shapper.pdf.

[21] L. J.M. Vermulst, C. Vervoorn, A. M. Boelens-Quist, H. P.F. Koppeschaar, W. B.M. Erich, J. H.H. Thijssen, and W. R. De Vries. Analysis of seasonal training volume and working capacity in elite female rowers. International Journal of Sports Medicine, 12(6):567-572, 1991. ISSN 01724622. doi: $10.1055 / \mathrm{s}-2007-1024735$.

[22] John H.M. Brooks, Colin W. Fuller, Simon P.T. Kemp, and Dave B. Reddin. An assessment of training volume in professional rugby union and its impact on the incidence, severity, and nature of match and training injuries. Journal of Sports Sciences, 26(8):863-873, 2008. ISSN 02640414. doi: 10.1080/02640410701832209.

[23] Jenny Jacobsson, Toomas Timpka, Jan Kowalski, Sverker Nilsson, Joakim Ekberg, Örjan Dahlström, and Per A Renström. Injury patterns in Swedish elite athletics: annual incidence, injury types and risk factors. British Journal of Sports Medicine, 47(15):986-991, 2013. ISSN 03063674. doi: 10.1136/bjsports-2013-092676.

[24] Paula C. Charlton, Dan Ilott, Russell Borgeaud, and Michael K. Drew. Risky business: An example of what training load data can add to shared decision making in determining 'acceptable risk'. Journal of Science and Medicine in Sport, 20(6):526-527, 2017. ISSN 18781861. doi: 10.1016/j.jsams.2016.10.006. 
[25] Rasmus Østergaard Nielsen, Erik Thorlund Parner, Ellen Aagaard Nohr, Henrik Sørensen, Martin Lind, and Sten Rasmussen. Excessive progression in weekly running distance and risk of runningrelated injuries: An association which varies according to type of injury. Journal of Orthopaedic and Sports Physical Therapy, 44(10):739-747, 2014. ISSN 01906011. doi: 10.2519/jospt.2014.5164.

[26] Brent Rogalski, Brian Dawson, Jarryd Heasman, and Tim J. Gabbett. Training and game loads and injury risk in elite Australian footballers. Journal of Science and Medicine in Sport, 16(6): 499-503, 2013. ISSN 14402440. doi: 10.1016/j.jsams.2012.12.004.

[27] E Twitchett, Manuela Angioi, Yiannis Koutedakis, and MA Wyon. The Demands of a Working Day Among Female Professional Ballet Dancers. Journal of dance medicine 83 science, 14(4): 127-132, 2010.

[28] Melanie Fuller, Gene M. Moyle, Andrew P. Hunt, and Geoffrey M. Minett. Ballet and Contemporary Dance Injuries When Transitioning to Full-Time Training or Professional Level Dance: A Systematic Review. Journal of dance medicine 83 science : official publication of the International Association for Dance Medicine \& Science, 23(3):112-125, 2019. ISSN 1089313X. doi: 10.12678/1089-313X.23.3.112.

[29] M. Fuller, G. M. Moyle, and G. M. Minett. Injuries across a pre-professional ballet and contemporary dance tertiary training program: A retrospective cohort study. Journal of Science and Medicine in Sport, 23(12):1166-1171, 2020. ISSN 18781861. doi: 10.1016/j.jsams.2020.06.012.

[30] M. Fuller, G. M. Moyle, A. P. Hunt, and G. M. Minett. Injuries during transition periods across the year in pre-professional and professional ballet and contemporary dancers: A systematic review and meta-analysis. Physical Therapy in Sport, 44:14-23, 2020. ISSN 18731600. doi: 10.1016/j.ptsp.2020.03.010. 